\title{
Influence of culture substrate on the phytochemical contents of fruiting bodies and spores of 3 varieties of Ganoderma lucidum
}

\author{
Zuofa ZHANG ${ }^{1,}$, , Weiming CAI ${ }^{1, b^{*}}$, Guoying LV ${ }^{1, c}$, Chaoqian $\mathrm{LI}^{2, \mathrm{~d}}$, Ying \\ WANG $^{3, e}$
}

${ }^{1}$ Institute of Horticulture, Zhejiang Academy of Agricultural Science, Hangzhou 310021, China

${ }^{2}$ Xinglong Biological technology co., LTD, Longquan, Zhejiang, 310000, China

${ }^{3}$ Zhejiang Shouxiangu Biology Sci-tech Co., Ltd. Wuyi, Zhejiang 321200, China

azzf2050@163.com, ${ }^{\mathrm{b} C a i w m 527 @ 126 . c o m, ~}{ }^{\mathrm{Cl}}$ Igybdz@163.com, ${ }^{\mathrm{d} l i c h a q i a n @ s o h u . c o m, ~}$

ewangying528@163.com

Keywords: Ganoderma lucidum; Culture substrate; Phytochemical contents

Abstract The aim of this research was to evaluate the influence of culture substrate on the phytochemical contents of fruiting bodies and spores of 3 different varieties of Ganoderma lucidum. Three varieties (Longzhi No.1, Hunong No.1 and Xianzhi No.1) of G. lucidum were cultivated in two culture substrates (wood cultivation and substitute cultivation). Substitute-cultivated G. lucidum mushrooms exhibited higher phytochemical contents (polysaccharides, total triterpenoids and total phenolic) in fruiting body than wood-cultivated G. lucidum mushrooms. On the contrary, the polysaccharide and total triterpenoid content in wood -cultivated G. lucidum were higher than in substitute-cultivated G. lucidum. The fruiting body exhibited higher phytochemical contents than spores in G. lucidum. The current study provides useful information on mushroom cultivation and the effective utilization of G. lucidum in food processing.

\section{Introduction}

Ganoderma lucidum (Lingzhi), a traditional medicinal fungus, is effective in treating hypertension, allergies, inflammation, hyperglycaemia, and cancer [1, 2]. Polysaccharides, triterpenoids and phenolic compounds are the major pharmacologically active components in $G$. lucidum and constitute the phytochemcial components of G. lucidum [3-7]. Wild mushrooms of $G$. lucidum are very rare in nature and are not sufficient for commercial exploitation. In order to meet the increasing demands of international markets, a large number of studies relating to the artificial cultivation have been reported [8]. Wood cultivation and substitute cultivation are the most 
important methods of artificial cultivation. In the present study, the effects of wood cultivation and substitute cultivation on polysaccharides, total triterpenoids and total phenolic contents in 3 varieties of G. lucidum (Longzhi No.1, Hunong No.1 and Xianzhi No.1) were investigated.

\section{Materials and methods}

\section{Sample preparation}

Samples of the fruiting bodies and spores of G. lucidum were collected from the farm of the Zhejiang Academy of Agricultural Science. The fruiting bodies were dried in a forced-draught oven at $60{ }^{\circ} \mathrm{C}$ for about $24 \mathrm{~h}$ upon acquisition. The samples were cleaned by brushing off soil dust from the surface and ground to fine pieces with a blender. The ground samples were sifted through a 20 $\mathrm{mm}$ mesh. These sifted powders were used for further analysis. The spore was dried and wall-broken for further use.

\section{Determination of active compounds}

The polysaccharide content was determined according to the method of Heleno et al. [9]. The total triterpenoids contents were determined according to the methods of Zhou et al. [10] and the total phenolic content was determined using the Folin-Ciocalteu reagent [11].

Statistical analysis

All the experiments were carried out in triplicate and data were expressed as mean \pm standard deviation. Statistical analysis was performed with ANOVA followed by Student's $t$-test. A level of $P<0.05$ was taken as statistically significant.

Table 1. Effect of culture substrate on the phytochemical contents of the fruiting body of 3 varieties of Ganderma lucidum

\begin{tabular}{ccccc}
\hline Variety & culture substrate & $\begin{array}{c}\text { Polysaccharide content } \\
(\mathrm{mg} \text { glucose/g dry materials })\end{array}$ & $\begin{array}{c}\text { Total triterpenoids contents } \\
(\mathrm{mg} \text { ursolic acid/g dry materials })\end{array}$ & $\begin{array}{c}\text { Total phenolic content } \\
(\mathrm{mg} \text { GAE/g dry materals })\end{array}$ \\
\hline Longzhi No.1 & Substitute culture & $28.83 \pm 1.15^{\mathrm{a}}$ & $13.68 \pm 0.57^{\mathrm{a}}$ & $14.2 \pm 2.57^{\mathrm{a}}$ \\
& Wood culture & $24.13 \pm 1.83^{\mathrm{b}}$ & $15.82 \pm 1.09^{\mathrm{b}}$ & $16.44 \pm 4.21^{\mathrm{a}}$ \\
\multirow{2}{*}{ Hunong No.1 } & Substitute culture & $30.48 \pm 2.34^{\mathrm{a}}$ & $13.29 \pm 1.84^{\mathrm{a}}$ & $20.82 \pm 1.89^{\mathrm{a}}$ \\
& Wood culture & $26.56 \pm 1.69^{\mathrm{a}}$ & $26.13 \pm 1.72^{\mathrm{b}}$ & $27.76 \pm 3.66^{\mathrm{b}}$ \\
\multirow{2}{*}{ Xianzhi No.1 } & Substitute culture & $24.13 \pm 1.22^{\mathrm{a}}$ & $27.24 \pm 3.35^{\mathrm{a}}$ & $22.74 \pm 2.09^{\mathrm{a}}$ \\
& Wood culture & $21.18 \pm 0.98^{\mathrm{b}}$ & $17.73 \pm 2.86^{\mathrm{b}}$ & $15.05 \pm 1.96^{\mathrm{b}}$ \\
\hline
\end{tabular}

Values are presented as mean \pm standard deviation $(N=3)$. Means with different lower case letters with in a column are significantly different for the same varieties. 


\section{Results and discussion}

\section{Phytochemical content}

As shown in Table 1 and Table 2, polysaccharides, total triterpenoids and total phenolic contents were determined from fruiting body and spores of 3 varieties (Longzhi No.1, Hunong No.1 and Xianzhi No.1) of G. lucidum that were cultivated in different culture substrates (wood cultivation and substitute cultivation). In the fruiting body of G. lucidum, the polysaccharide content of the different samples varied from 21.18 to $30.48 \mathrm{mg}$ glucose/g dry material. It was interesting to observe that the substitute-cultivated mushrooms have higher polysaccharide contents than the wood-cultivated mushrooms in all the three varieties. Compared to wood cultivation, substitute cultivation has better distribution and availability of nutrients that allows for better absorption of nutrients, resulting in faster growth and increased polysaccharide contents. For the total triterpenoids and total phenolic contents, the results in Longzhi No.1 and Hunong No.1 were the same to the polysaccharide content. However, in substitute-cultivated Xianzhi No. 1, the total triterpenoid and phenolic contents of the fruiting body were $27.24 \mathrm{mg}$ ursolic acid/g dry material and $22.74 \mathrm{mg} \mathrm{GAE} / \mathrm{g}$ dry material, respectively. The total triterpenoid and total phenolic contents of wood-cultivated Xianzhi No.1 were reduced to $17.73 \mathrm{mg}$ ursolic acid/g dry material and $15.05 \mathrm{mg}$ GAE/g dry material, respectively.

In the spores of G. lucidum, it was interesting to note that the polysaccharide and total triterpenoids contents in wood cultivation were higher than those obtained from substitute cultivation in all the 3 tested varieties. On the contrary, the total phenolic content in substitute-cultivated G. lucidum was higher than that obtained from wood-cultivated G. lucidum in all 3 tested varieties.

Table 2. Effect of culture substrate on the phytochemcial contents of the spores of 3 varieties of Ganderma lucidum

\begin{tabular}{ccccc}
\hline Variety & culture substrate & $\begin{array}{c}\text { Polysaccharide content } \\
(\text { mg glucose/g dry materials })\end{array}$ & $\begin{array}{c}\text { total triterpenoids contents } \\
(\text { mg Ursolic acid/g dry materials })\end{array}$ & $\begin{array}{c}\text { Total phenolic content } \\
(\text { mg GAE/g dry materals })\end{array}$ \\
\hline Longzhi No.1 & Substitute culture & $36.89 \pm 0.57^{\mathrm{a}}$ & $8.93 \pm 0.86^{\mathrm{a}}$ & $10.57 \pm 0.53^{\mathrm{a}}$ \\
& Wood culture & $41.33 \pm 1.76^{\mathrm{b}}$ & $9.19 \pm 0.52^{\mathrm{a}}$ & $8.75 \pm 0.98^{\mathrm{b}}$ \\
\multirow{2}{*}{ Hunong No.1 } & Substitute culture & $34.77 \pm 1.45^{\mathrm{a}}$ & $10.46 \pm 0.37^{\mathrm{a}}$ & $10.14 \pm 0.88^{\mathrm{a}}$ \\
& Wood culture & $36.85 \pm 1.11^{\mathrm{a}}$ & $11.79 \pm 0.77^{\mathrm{b}}$ & $6.94 \pm 1.05^{\mathrm{b}}$ \\
\multirow{2}{*}{ Xianzhi No.1 } & Substitute culture & $33.42 \pm 1.29^{\mathrm{a}}$ & $8.46 \pm 0.48^{\mathrm{a}}$ & $10.78 \pm 1.38^{\mathrm{a}}$ \\
& Wood culture & $39.26 \pm 1.54^{\mathrm{b}}$ & $9.86 \pm 0.65^{\mathrm{b}}$ & $7.79 \pm 0.89^{\mathrm{b}}$ \\
\hline
\end{tabular}

Values are presented as mean \pm standard deviation $(N=3)$. Means with different lower case letters with in a column are significantly different for the same varieties. 


\section{Conclusions}

In the present study, the influence of culture substrates on the phytochemical contents of the fruiting bodies and spores of 3 varieties of G. lucidum, was investigated. Three varieties (Longzhi No.1, Hunong No.1, and Xianzhi No.1) and 2 culture substrates (wood cultivation and substitute cultivation) were investigated. Substitute-cultivated mushrooms of G. lucidum exhibited higher phytochemical contents (polysaccharides, total trierpenoids and total phenolic content) than wood-cultivated mushrooms of G. lucidum in the fruiting body. On the contrary, the polysaccharide and total triterpenoid content in wood-cultivated varieties of G. lucidum were higher than those in substitue-cultivated varieties of G. lucidum. The fruiting bodies exhibited higher phytochemcial contents than the spores in G. lucidum. The current study provides useful information on mushroom cultivation and the effective utilization of G. lucidum in food processing.

\section{Acknowledgments}

This research was financially supported by New Variety Breeding Project of Science Technology Department of Zhejiang Province (2016CO2057).

\section{References}

[1] H. Maruyama, K. Yamazaki, S. Murofushi, C. Konda and T. Ikekawa: J. Pharmacobio-dyn. Vol. 12 (1989), p. 118-123.

[2] T. Miura, L. Yuan, B.X. Sun, H Fum, M. Yoshida, K Wakame and K. Kosuna: Biosci. Biotech. Biochem. Vol. 66 (2002), p. 2626-2631.

[3] Y.S. Song, S.H. Kim, J.H. Sa, C. Jin, C.J. Lim and E.H. Park: J. Ethnopharmacol. Vol. 90 (2004), p. 17-20.

[4] J. Jia, X. Zhang, Y.S.Hu, Y.Wu, Q.Z.Wang and N.N. Li: Food Chem. Vol. 115 (2009), p. 32-36.

[5] T.P. Smina, S.De, T.P. Devasagayam, S.Adhikari and K.K. Janardhanan: Mutation Res. Vol. 726 (2011), p. 188-194.

[6] G. Stanley, K. Harvey, V. Slivova, J. Jiang and D. Sliva: Biochem. Biophys. Res. Commun. Vol. 330 (2005), p. 46-52.

[7] D. Birt: J. Am. Diet. Assoc. Vol. 106 (2006), p. 20-21.

[8] M. Berovic, J. Habijanic, I. Zore, B. Wraber, D. Hodzar, B. Boh and F. Pohleven: J. Biotech. Vol. 
103(2003), p.77-86.

[9] S.A.Heleno, L. Barros, A. Martins, M.R.P. Queiroz, C. Santos-Buelga andI.C.F.R. Ferreira: Food Res. Int. Vol. 46(2012), p.135-140.

[10] S. Zhou, J.S. Zhang, Y.F. Liu, D.Wu, H. Zhang, Y. Yang and Q.J. Tang: Acta edulis fungi Vol. 18 (2011), p. 67-70.

[11] Y. Zhao, S.K. Du, H.X. Wang and M. Cai: Food Chem. Vol. 152 (2014), p. 462-466. 